\begin{tabular}{|c|c|}
\hline & $\begin{array}{c}\text { JURNAL ILMIAH } \\
\text { STOK BINA GUNA MEDAN } \\
\text { Volume } 2 \text { Nomor } 1 \text {; Maret } 2020\end{array}$ \\
\hline
\end{tabular}

PENERAPAN VARIASI PEMBELAJARAN UNTUK MENINGKATKAN HASIL BELAJAR PUKULAN FOREHAND DRIVE PERMAINAN TENIS MEJA PADA SISWA KELAS VIII SMP MUHAMMADIYAH 3 MEDAN TAHUN AJARAN 2018/2019

\title{
APPLICATION OF LEARNING VARIATIONS TO IMPROVE THE LEARNING OUTCOMES OF THE FOREHAND DRIVE TABLE TENNIS GAME IN CLASS STUDENTS VIII JUNIOR HIGH SCHOOL MUHAMMADIYAH 3 MEDAN ACADEMIC YEAR 2018/2019
}

\author{
Pedomanta Keliat \\ Sekolah Tinggi Olahraga dan Kesehatan Bina Guna \\ J1. Alumunium Raya, Sumatera Utara, 20241, Indonesia \\ email : keliatpedomanta@gmail.com
}

\begin{abstract}
ABSTRAK
Penelitian ini bertujuan untuk mengetahui peningkatan hasil belajar Pukulan forehand drive tenis meja pada siswa kelas VIII SMP Muhammadiyah 3 Medan Tahun Ajaran 2018/2019 melalui Variasi Pembelajaran Penelitian ini merupakan penelitian tindakan kelas. Penelitian dilaksanakan dalam dua siklus, dengan teknik analisa data yang digunakan dalam penelitian ini adalah secara deskriptif yang didasarkan pada analisis kualitatif dengan persentase : (1) Dari tes hasil belajar sebelum menggunakan variasi pembelajaran diperoleh 27 siswa (90\%) yang belum mencapai tingkat ketuntasan belajar, sedangkan 3 siswa (10\%) sudah mencapai tingkat ketuntasan belajar. Kemudian dilakukan pembelajaran menggunakan variasi pembelajaran (2) dari tes hasil belajar melalui variasi pembelajaran di siklus I diperoleh 14 siswa $(46,67 \%)$ yang mencapai tingkat ketuntasan belajar, sedangkan 16 siswa $(53,33 \%)$ belum mencapai tingkat ketuntasan belajar. Dengan nilai rata-rata 70,9. Kemudian dilakukan kembali variasi pembelajaran (3) dari tes hasil belajar II di siklus II terdapat 21 siswa (70\%) yang mencapai tingkat ketuntasan belajar, sedangkan 9 siswa (30\%) belum mencapai tingkat ketuntasan belajar, dengan nilai rata-rata 8. Berdasarkan analisis data dapat dikatakan bahwa melalui variasi pembelajaran dapat meningkatkan hasil belajar Pukulan Forehand Drive Tenis Meja pada siswa kelas VIII SMP Muhammadiyah 3 Medan Tahun Ajaran2018/2019.
\end{abstract}

\section{Kata kunci: variasi pembelajaran, Forehand Drive Tenis Meja}

\begin{abstract}
This study aims to determine the increase in learning outcomes forehand drive table tennis drives in class VIII students of SMP Muhammadiyah 3 Medan Academic Year 2018/2019 through Learning Variations This research is a classroom action research. The study was conducted in two cycles, with data analysis techniques used in this study were descriptive based on qualitative analysis with the percentage: (1) From the test results of learning before using variations of learning obtained 27 students (90\%) who have not reached the level of mastery learning, while 3 students $(10 \%)$ have reached the level of mastery learning. Then learning is done using variations in learning (2) from the test of learning outcomes through learning variation in the first cycle obtained 14 students $(46.67 \%)$ who reached the level of mastery learning, while 16 students $(53.33 \%)$ have not reached the level of mastery learning.
\end{abstract}


With an average value of 70.9. Then the learning variation (3) from the second learning achievement test in the second cycle contained 21 students $(70 \%)$ who reached the level of mastery learning, while 9 students $(30 \%)$ had not reached the level of mastery learning, with an average value of 8 . Based on Data analysis can be said that through the variety of learning can improve learning outcomes in Table Tennis Forehand Drive in VIII grade students of Muhammadiyah Middle School 3 Medan Academic Year 2018/2019.

\section{Keywords: learning variations, Forehand Drive Table Tennis}

\section{PENDAHULUAN}

Pendidikan jasmani olahraga dan kesehatan memberikan kesempatan pada siswa untuk terlibat langsung dalam aneka pengalaman belajar melalui aktifitas jasmani, bermain dan berolahraga yang dilakukan secara sistematis, terarah danterencana. Hal tersebut sesuai dengan kebutuhan dasar setiap manusia (Sabaruddin, 2016) pendidikan merupakan kebutuhan dasar setiap manusia untuk menjamin keberlangsungan hidupnya agar lebih bermartabat. Pendapat yang sama juga mengatakan bahwa pendidikan jasmani pada pengertiannya adalah proses pendidikan yang memanfaatkan aktifitas fisik untuk menghasilkan perubahan holistik dalam kualitas individu, baik dalam hal fisik, mental, serta emosional.

Pendidikan jasmani memperlakukan anak sebagai sebuah kesatuan utuh, makhluk total, daripada hanya menganggapnya sebagai seseorang yang terpisah kualitas fisik dan mentalnya (Sinulingga, 2013). Materi pendidikan jasmani terdiri dari permainan bola kecil, permainan bola besar, atletik, senam, kegiatanair, dan pola hidup kesehatan. Setiap peserta didik harus memenuhi kualifikasi kompetensi materi dengan proses pengajaran yang disampaikan oleh guru Penjas (Rinaldi, 2019).

Pembekalan pengalaman belajar melalui proses pembelajaran pendidikan jasmani olahraga dan kesehatan dengan mengajarkan berbagai keterampilan gerak dasar, teknik dan strategi permainan olahraga, internalisasi nilai- nilai (sportifitas, kejujuran, kerjasama dan lainlain). Pelaksanaan pendidikan jasmani dan olahraga merupakan sebuah investasi jangka panjang dalam upaya pembinaan mutu Sumber Daya Manusia (SDM).

Indonesia pada tahun 2045 disebut dengan Indonesia emas, yang mana pada saat itu menjadi sebuah impian besar tentang Indonesia yang unggul, maju bersaing dengan bangsa-bangsa lain, dan telah cukup dewasa untuk mengatasi isu-isu persoalan klasik bangsa (AAP Karo-karo, 2018). Pendidikan dijadikan sebagai sarana atau wahana yang berfungsi untuk meningkatkan kualitas manusia, baik aspek kemampuan, kepribadian, maupun kewajiban sebagai warga negara yang baik. (AAP Karo-karo, 2018).

Karena itu, upaya pembinaan bagi masyarakat dan peserta didik melalui pendidikan jasmani dan olahraga perlu 
terus dilakukan untuk itu pembentukan sikap dan pembangkitan motifasi dan dilakukan pada setiap jenjang pendidikan formal. Guru sebagai penyelenggara pendidikan sekaligus motivator utama dalam proses pembelajaran mempunyai peranan yang amat penting dalam rangka pencapaian tujuan pendidikan, disamping itu kualitas guru sangat berpengaruh terhadap kualitas anak didik.

Guru dalam proses pembelajaran harus mampu merencanakan, menetapkan tujuan, mempersiapkan materi, memilih metode dan variasi pembelajaran serta alat bantu yang tepat dalam proses pembelajaran. Sinulingga mengatakan bahwa guru sebagai tenaga pendidik harus berupanya mengembangkan kompetensi yang dimiliki demi tercapainya tujuan pendidikan

Lemahnya proses pembelajaran yang dikembangkan guru saat ini merupakan salah satu masalah yang dihadapi didunia pendidikan. Proses pembelajaran yang terjadi didalam kelas dilaksanakan sesuai dengan kemampuan dan selera guru, pada kenyataannya kemampuan guru dalam pengelolahan pembelajaran tidak merata.

Untuk menunjang pelaksanaan pembelajaran disekolah, kreativitas seorang guru sangat dibutuhkan, termasuk memberi pengalaman belajar yang baik secara lengkap kepada anak didik. Fenomena ini merupakan sebuah masalah akibat kurangnya kemampuan sebagian guru Penjas dalam memanfaatkan perannya sebagai yang memiliki potensi sesuai dengan tuntutan target kurikulum dan daya serap sebagai pendidik yang kreatif dalam mengaktifkan pembelajaran penjas di sekolah.

Untuk menumbuhkan sikap aktif, kreatif, inovatif, dan kompetitif dari siswa tidaklah mudah, fakta yang terjadi adalah guru dianggap sumber belajar paling benar. Proses pembelajaran yang terjadi memposisikan siswa sebagai pendengar ceramah guru. Akibatnya proses belajar mengajar cenderung membosankan dan menjadikan siswa malas belajar. Sikap anak didik yang pasif tersebut ternyata tidak hanya terjadi pada mata pelajaran tertentu sajatetapi pada hampir semua mata pelajaran termasuk penjas. Sebenarnya banyak cara yang dilakukan dengan menerapkan pembelajaran dengan bantuan variasi pembelajaran.

Tenis Meja adalah salah satu jenis cabang olahraga yang populer di Dunia. Di indonesia olahraga ini sudah tidak asing lagi. Olahraga ini dulunya sering disebut Ping-pong. Pada materi pembelajaran tenis meja teknik dasar yang paling sulit dipahami siswa untuk mempraktekkannya dengan tepat adalah teknik saat memukul bola. Dimana siswa sangat sulit mengkordinasikan gerakan dengan kondisi bola. Serta siswa tidak melakukan teknik gerakan dengan baik dan benar.

Dalam permainan tenis meja terdapat 
berbagai teknik dasar meliputi teknik memegang bet (grip), teknik siap (stance), teknik gerak kaki ( footwork), dan teknik pukulan (stroke). Teknik pukulan merupakan salah satu teknik dasar yang bertujuan untuk memindahkan bola kearah lawan dan untuk menghasilkanpoin.

Dari hasil observasi yang penulis lakukan di SMP Muhammadiyah 3 Medanserta informasi yang diperoleh dari guru penjas pada bahasan tenis meja bahwasanya selama ini guru penjas dalam proses pembelajarannya menggunakan metode komando. Guru hanya menyuruh siswa melakukan gerakan pukulan forehand drive permainan tenis meja tanpa memberitahukan bagaimana tahapan tahapan melakukannya sehingga tidak semua siswa akan mudah memahami dan mengerti tentang materi pelajaran yang disampaikan olehgurunya.

Setelah itu guru membiarkan siswanya bermain tenis meja tanpa memantau kembali pukulan forehand drive nya dan hanya siswa yang bisa saja yang melakukan sementara siswa yang lain tidak melaksanakan pembelajaran tersebut. Sehingga banyak siswa yang tidak bisa melakukan pukulan forehand drive permainan tenis meja karena mereka tidak bisa mengkordinasikan antara gerakan badan dan tangan dengan bola. Serta minimnya variasi-variasi pembelajaran yang diberikan guru mengakibatkan siswa kurang maksimal dalam mengikuti pembelajaran pendidikan jasmani khususnya materi tenis meja karena siswa merasa jenuh dan bosan mengikuti pembelajaran penjaskes.

Bedasarkan hasil observasi yang penulis lakukan di SMP Muhammadiyah 3 Medan pada jam pelajaran penjas pokok bahasan tenis meja khususnya pada saat siswa mempraktekkan apa yang telah dijelaskan oleh gurunya, informasi yang diperoleh dari guru penjas dari 30 siswa yang ada dikelas VIII hanya ada 4 siswa yang nilai > 75 dan 26 siswa yang mendapat nilai $<75$. dari hasil observasi tersebut dapat di simpulkan nilai yang diperoleh siswa belum memenuhi Kriteria Ketuntasan Minimum (KKM) penjas disekolah tersebut. Hampir rata - rata siswa tidak dapat melakukan pukulan forehand drive permainan tenis meja dengan baik dan benar karena mereka tidak bisa mengkordinasikan antara gerakan badan dan tangan dengan datangnyabola.

Hal ini menunjukkan bahwa kurangnya variasi pembelajaran dan perhatian guru, sehingga mengakibatkan kegiatan hasil belajar masih kurang maksimal. Disamping itu peserta didik merasa jenuh dan bosan dalam mengikuti pelajaran karena tidak melibatkan siswa berinteraksi dalam kegiatan hasil belajar mengajar karena tidak menggunakan variasi pembelajaran yang hanya menggunakan metode komando.

Sejalan dengan hal itu dalam penggunaan variasi pembelajaran sebagai 
alat bantu pelaksanaan mengajar merupakan salah satu bentuk pendekatan yang bisa diharapkan dalam meningkatkan hasil belajar. Pendidikan jasmani dalam hakekatnya adalah belajar gerak, dimana fungsi motorik seseorang itu disiapkan sedemikian rupa untuk bisa menuju kearah perubahan tingkah laku sebagai hasil belajar.

Dari uraian diatas, salah satu metode belajar untuk dapat trampil bermain tenis meja adalah guru memberikan variasi variasi pembelajaran agar siswa dapat menguasai permainan tenis meja. Karena variasi dalam tenis meja adalah salah satu faktor yang menentukan keberhasilan seorang pemain dalam bermain tenis meja. Sehingga peneliti ingin melaksanakan penelitian dengan judul " Penerapan Variasi Pembelajaran Untuk Meningkatkan Hasil Belajar Pukulan Forehand Drive Permainan Tenis Meja Pada Siswa Kelas VIII SMP Muhammadiyah 3 Medan Tahun Ajaran 2018/2019.

\section{METODE PENELITIAN}

Penelitian ini merupakan penelitian tindakan kelas (PTK). Penelitian dilaksanakan dalam dua siklus, dengan setiap siklus terdiri atas perencanaan, pelaksanaan tindakan, observasi, danrefleksi.Sumber data dalam penelitian ini adalah hasil tes siswa yang berbentuk aplikasi Pukulan Forehand Drive Tenis Meja. Teknik pengumpulan data dengan penilaian hasil belajar Pukulan Forehand
Drive TenisMeja.Teknikanalisa data yang digunakan dalam penelitian ini adalah secara deskriptif yang didasarkan pada analisis kualitatif dengan persentase.

\section{HASIL DAN PEMBAHASAN}

Tes yang diberikan kepada siswa berupa tes pukulan forehand drive tenis meja.Penilaian dilakukan oleh tiga tester yang menilai sesuai dengan indikator dan posisi yang sudah ditetapkan. Adapun deskripsi data penilaian yang diperoleh dapat dilihat dari tabel di bawah:

Tabel 1. Deskripsi Data Awal Penelitian

\begin{tabular}{|c|c|c|c|c|}
\hline \multirow[t]{2}{*}{ No } & \multirow{2}{*}{$\begin{array}{l}\text { Hasil } \\
\text { Tes }\end{array}$} & \multirow[b]{2}{*}{$\begin{array}{c}\text { Jumlah } \\
\text { siswa }\end{array}$} & \multirow[b]{2}{*}{$\%$} & \multirow[b]{2}{*}{ Ket } \\
\hline & & & & \\
\hline 1 & $\begin{array}{l}\text { Sikap } \\
\text { Awal }\end{array}$ & 3 & $3.67 \%$ & Tuntas \\
\hline 2 & $\begin{array}{l}\text { Sikap } \\
\text { pelaksa } \\
\text { n } \\
\text { aan }\end{array}$ & 27 & $97.33 \%$ & $\begin{array}{l}\text { Tidak } \\
\text { tuntas }\end{array}$ \\
\hline \multicolumn{2}{|c|}{ Jumlah } & 30 & $100 \%$ & \\
\hline
\end{tabular}

Dari tabel di atas dapat dilihat bahwa pada pre-test dari 30 orang siswa hanya 3 orang yang tuntas dan 27 orang lainnya tidak tuntas dalam pembelajran forehand drive tenismeja

Setelah data terkumpul maka dilakukan analisis (1) Dari tes hasil belajar sebelum menggunakan variasi pembelajaran diperoleh 27 siswa (90\%) yang belum mencapai tingkat ketuntasan belajar, sedangkan 3 siswa (10\%) sudah mencapai tingkat ketuntasan belajar. Kemudian dilakukan pembelajaran 
menggunakan variasi pembelajaran (2) dari tes hasil belajar melalui variasi pembelajaran di siklus I diperoleh 14 siswa $(46,67 \%)$ yang mencapai tingkat ketuntasan belajar, sedangkan 16 siswa $(53,33 \%)$ belum mencapai tingkat ketuntasan belajar. Dengan nilai rata-rata 70,9. Kemudian dilakukan kembali variasi pembelajaran (3) dari tes hasil belajar II di siklus II terdapat 21 siswa (70\%) yang mencapai tingkat ketuntasan belajar, sedangkan 9 siswa (30\%) belum mencapai tingkat ketuntasan belajar, dengan nilai rata-rata 8. Dalam hal ini dapat dilihat bahwa terjadi peningkatan nilai rata-rata hasil belajar siklus I ke siklus II. Berdasarkan analisis data dapat dikatakan bahwa melalui variasi pembelajaran dapat meningkatkan hasil belajar Pukulan Forehand Drive Tenis Meja pada siswa kelas VIII SMP Muhammadiyah 3 Medan Tahun Ajaran2018/2019.

\section{KESIMPULAN}

Dalam hal ini dapat dilihat bahwa terjadi peningkatan nilai rata-rata hasil belajar siklus I ke siklus II. Berdasarkan analisis data dapat dikatakan bahwa melalui variasi pembelajaran dapat meningkatkan hasil belajar Pukulan Forehand Drive Tenis Meja pada siswa kelas VIII SMP Muhammadiyah 3 Medan Tahun Ajaran2018/2019.

\section{DAFTAR PUSTAKA}

$\begin{array}{cr}\text { Karo-Karo, Alan } & \text { Alfiansyah } \\ \text { Putra (2018) Nilai-Nilai } & \text { Pendidikan } \\ \text { Karakter Melalui } & \text { Pembelajaran Pencak } \\ \text { Silat. In: Seminar Nasional Pendidikan } \\ \text { Olahraga, 08 September 2018, Gedung } \\ \text { Digital Library Lantai Iv Universitas } \\ \text { Negeri Medan. }\end{array}$

Karo-Karo, Alan Alfiansyah Putra And Wibowo, Reza (2018) Pencegahan Penyalahgunaan Narkoba Melalui Pembelajaran Pendidikan Jasmani. In: Seminar Nasional Pendidikan Olahraga, Sabtu, 08 September 2018, Gedung Digital Library Lantai Iv Universitas Negeri Medan.

Sinulingga, A., Suprayitno, S., \& Pertiwi, D. (2019). Professionalism of physical education teachers: from the leadership of school principals, school culture to teacher work motivation. Jurnal SPORTIF: Jurnal Penelitian Pembelajaran, 5(2), 296. https://doi.org/10.29407/js_unpgri.v5i $\underline{2.13113}$

Sinulingga, A., \& Nugraha, T. (2013). Penerapan Pendekatan Ilmiah Pada Pelajaran Pendidikan Jasmani Olahraga Dan Kesehatan Dan Dampaknya Pada Siswa Sma Negeri 15 Medan. Jurnal Pedagogik Olahraga, 53(9), 1689-1699. https://doi.org/10.1017/CBO97811074 15324.004

Sabaruddin Yunis. 2016. Pengembangan Pengetahuan Anak Difabel Melalui Pendidikan Jasmani Olahraga dan Outbound. Journal Physical Education, Health and Recreation. Vol 1, No 1. Hal 70-77.

Rinaldi Aditya. Boby Helmi. Khairul Usman. (2019). Pengembangan Peralatan Modifikasi Atletik Pada Pembelajaran PJOK Tingkat Sekolah 
Dasar. Jurnal Ilmiah Stok Bina Guna

Medan. 7.(2) 17-23. 